\title{
Status of business model and electronic market research: An interview with Alexander Osterwalder
}

\author{
Rainer Alt • Hans-Dieter Zimmermann
}

Published online: 26 November 2014

(C) Institute of Information Management, University of St. Gallen 2014

\begin{abstract}
This interview with Alexander Osterwalder provides a compelling view on how research on business models emerged and describes how business model thinking makes a difference in practice. It shows that business models are vital for systematically addressing and (re)designing the key strategic aspects of each business. It is based on Alexander Osterwalder's doctoral work on business models which was
\end{abstract}

published ten years ago as well as his experiences of making a business model around business models. Besides illustrating the argumentation with many examples the interview also raises the question of rigor and relevance for academic research.

Keywords Business model research · Business strategy · Rigor and relevance

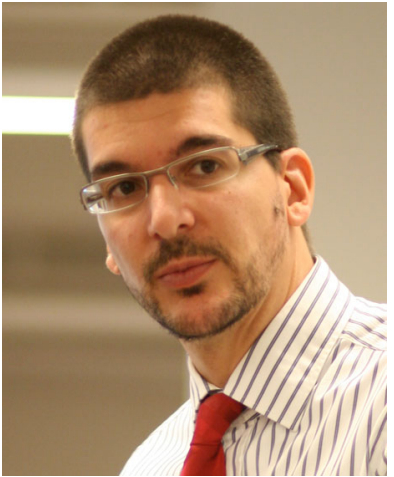

Alexander Osterwalder

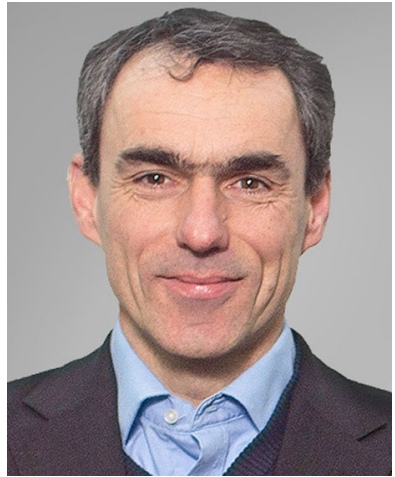

Rainer Alt

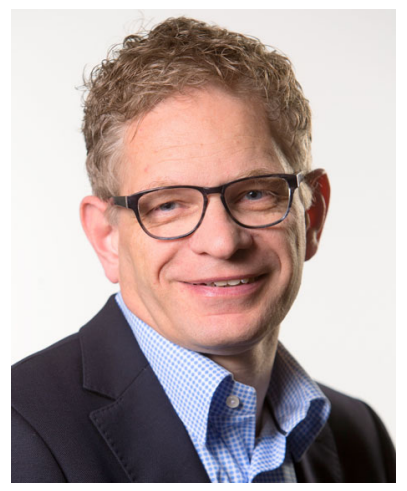

Hans-Dieter Zimmermann
R. Alt $(\bowtie)$

Information Systems Institute, University of Leipzig,

Grimmaische Str. 12, 04109 Leipzig, Germany

e-mail: rainer.alt@uni-leipzig.de

\section{H.-D. Zimmermann}

FHS St. Gallen, University of Applied Sciences, Rosenbergstrasse 59, 9001 St. Gallen, Switzerland e-mail: hansdieter.zimmermann@fhsg.ch

\section{Background information on Alexander Osterwalder}

In 2004, Alexander Osterwalder finished his Ph.D. on "The Business Model Ontology_A Proposition in a Design Science Approach" at the University of Lausanne, Switzerland. As per October 2014, this thesis (Osterwalder 2004) has received 1'103 citations (based on Harzing per October 2014) and generated more impact than most other dissertations. In particular, Alexander not only wrote about the specification of business models, but also succeeded in establishing a business model 
around business models. In the past 10 years he has not only published international leading books, such as Business Model Generation (Osterwalder and Pigneur 2010), but has also become a passionate entrepreneur and a demanded speaker. He cofounded Strategyzer, a software company specializing in tools and content for strategic management and innovation. The impact of his doctoral work may be seen when looking at the "Business Model Canvas", a model that is not only referenced in the academic literature, but also used as a strategic management tool to design, test, build, and manage business models by companies, such as Coca Cola, GE, P\&G, Mastercard, Ericsson, LEGO, or 3M. In parallel to his entrepreneurial success Alex has kept close ties with the academic world and lectures, among others, at Berkeley, MIT, IESE and IMD.

\section{The interview}

Held on May 28, 2014.

Electronic Markets (EM): What are your activities today? How would you describe your job?

Alexander Osterwalder (AO): There are two main things: One is being a software entrepreneur in the private sector and the other is to continue to be an author and thinker around concepts that are relevant to business people. I am deliberately keeping it broad because we started out with business models and now we are focusing on value propositions. I think we need these kind of tools, like the first one that we created. We also need the interaction with the academic world, which is more the concepts that you need in companies, without actually being an academic anymore.

EM: Could you explain what your position was back in 2004 and the years before?

AO: From 2000 to $2004 \mathrm{I}$ was a Ph.D. researcher at the MIS institution of HEC Lausanne working together with Yves Pigneur who became my co-author. He originated the idea to work on the topic of business models and we continued to work on it together. That was the original starting point, which was $100 \%$ academic. Mentally I still feel like an academic, and if you want, I am just not limited by the academic constraints of publishing and those kind of things. But I still continue research and we do this extremely well together with Yves Pigneur and other people as well.

EM: What was your motivation to focus on business models?

AO: After finishing my studies I did two job interviews. One was with McKinsey and one was with Yves Pigneur. Both were very interesting in the sense that one was going into the private sector in a consulting role having the opportunity to better understand and help companies. The other one was similar, but along a very different path. It was this topic of business models, which I found interesting because it allows you to explore the blueprint of a company. Basically it is the reason for a company's existence, right? I saw this like an opportunity to go beyond all the things I learned in information systems, in marketing or in whatever, to go deeper in the understanding of the enterprise. Because at the end of the day, businesses disappear without a sound business model. I like to say today that business models expire like a yogurt in a shelf. And it's inevitable, right? I just felt like this would be a topic that would allow me to explore the enterprise in a holistic way, which turned out to be absolutely true. The topic would allow me to understand companies in a holistic way, beyond the kind of detail topics, like marketing, like accounting, like management information systems. It provides you a good grasp on why companies exist. What gives them the right to survive? Well, a great business model.

EM: And why do you think have business models not been a topic before?

AO: That is an extremely interesting question. I think that this topic became popular when e-commerce and the Web became more broad, more widely accepted, and people were creating startups. It was a breaking point, in the sense that business models, and, in particular, some of the traditional business models were questioned. You could say that then people were not sure if their business models would survive. Later this turned out to be an absolutely correct assumption and, in fact, business models do not survive forever. I think that before the Internet became mainstream, business models had a longer shelf life. You could be a CEO or a manager and you could manage the same business model throughout your career. There was no need to change the business model and focusing on process redesign and the like were all the big topics, right? But when e-commerce emerged, people were starting to question the viability of business models. Take the Gartner hype cycle - there is this big jump at the beginning, everybody is afraid, and it turns out that, oh, it is not as dramatic. Over the longer term this actually is dramatic and that is exactly what happened. With e-commerce and then the bust, everybody was afraid and there was this big hype around business models, because we felt like it was a breaking point. It turned out to be less dramatic in the short-term, but much more dramatic than we might have expected in the long term. Because what happened in the e-commerce field now is having an impact on every industry. While it might have started out with everything digital, such as e-commerce and digital music, movies, and news, today banking, pharmaceutical companies and car manufacturers are affected. For other reasons than just the Internet, business models are today expiring everywhere. That is where you have the long part of the Gartner hype cycle, right? What we feared then is actually becoming reality today. Business models in every 
sector are changing dramatically. Take coffee. My favorite example is still Nespresso. They turned parts of an industry, which was transactional, selling coffee through retail, into one with recurring revenues. So locking the customer in, at least for a while, and then earning recurring revenues. That is a big shift, right? However, business model innovation and new business models evolve everywhere today. What happened then in e-commerce because of the Internet is now reality because of many other factors: the Internet, technology in general, globalization, changing customer needs, and transparency. That is a big shift.

EM: So digitalization via the Internet was an enabler or driver of the development. What in your opinion was the role of the technological and the management communities?

AO: The first dramatic wave was driven by the Internet, because we had more choices when it came to channels. We had different ways of collaborating, different ways of distribution. Everybody thought business model innovation only had to do with technology and for a very long time, that was the assumption: everything around innovation or business model innovation has to do with technology. But that was only the starting point. I think that this field was actually the driver. If you take management information systems, computer science, there is a tradition of making models to better understand the world. Making conceptual models to shape things, ideas, or you could say it happened with databases, it happened with accounting systems. There is this engineering tradition to approach the topic in a structured way, which is less a tradition in the management field. There you also have models, but maybe in a different kind of way. What was driving us then was this whole idea around design science. Like a third way of researching besides quantitative and qualitative research. Contrary to the traditional research in management, which was either quantitative or qualitative, in the management information systems field, you had the whole design science wave where you said, "Oh, no, it's actually very good to have constructs." There was this tradition and many people who were writing about this had pretty interesting conceptual models, right? I think that is another reason why it started out in that field. To a certain extent, today still people feel like innovation and business model innovation has much to do with technology, which I think is just one component. In our recent work, we show that you can redesign your business model just by using different building blocks, which are not necessarily always based on technology. Even if you take Nespresso, selling through the Internet is an important aspect, but it is the entire business model, which is attractive. Not just the fact that they use the Internet. Although we are beyond that point of just having technology as a driver today, I believe that technology was the main driver for business model innovation.
EM: That also links to your history because you did a Ph.D. in the MIS field?

AO: Yes, Yves is at the MIS department here, and I was in that tradition of the MIS department, kind of in between strategy and MIS. We wanted to come up with a model to describe business models that was rigid enough or constrained enough that you could build a management system on top of it. We were thinking of the computer-aided design that you have in architecture for business modelers. This was happening in the process field, but it was not yet happening at the strategic field. So here again you have this tradition of modeling in management information systems and this started out with finance and then it went to processes. I think we are now moving to the next level, which is business models. We are moving from very concrete stuff, such as operations and accounting, towards more abstract concepts, such as business models. In general, we believe that if you can model and describe them, then you can start managing them. Then you can start building an MIS around it. That was the theme of my dissertation: Can we build a MIS to design business models? That was the original topic and funny enough, that is exactly what our company, Strategyzer.com, is doing today. Fifteen years later, we are trying to make it reality.

EM: Before we focus on Strategyzer, would you change anything from hindsight in your dissertation, if you had the opportunity to re-write it again today?

AO: Absolutely not, but it is a learning process. From today's knowledge there are many things we could no doubt have done better, but which we - and when I say "we" it's not only together with Yves, but with our entire team - could not know back then. What I regret a little and what could have been better, is maybe the MIS prototype since the real system behind it was not as cool as it could have been. I could have gone further then maybe in the aspect of the prototype, but I was less on the computer science side, so I did not possess all the necessary skills to immediately design a great thing. Otherwise, we followed a good path and, in particular compared to other researchers, we really built on other models. We did not just try to come up with a new model, but we tried to build on everything that existed and synthesize from there. The big game changer for us was the test of the model in the field. In design science, there is this part where you need to validate your model. I talked with two different managers and entrepreneurs to figure out how this new model could represent their business models. Imagine you go to an entrepreneur and you say, "Oh, look, this is our model" and then you start sketching out his or her business model. They will immediately tell you whether it works. They will also tell you, "Oh, but here's an important part of my business model. It's not reflected in your model." I think that testing the model actually was the strong part of the Ph.D. and I am actually proud that we validated the model. In this kind of research, we often tend 
to come up with new models without stress testing them enough. People in companies might not adopt them as easily because we did not stress test them enough to make them ready for practice. While there were many good parts in the Ph.D., the things that have proven to be wrong or missing we could not have known back there. We learned them in practice afterwards.

EM: What do you think was your contribution to the field of business model research in the last, say, 14, 15 years?

AO: What I am proud about is the fact that people in companies, from startups all the way to the biggest multinationals you can imagine, and even governments and social enterprises started using the tools that we designed in academic research. By "tools" I am not referring to software tools. I mean the concepts. The business model canvas is an academic product, which comes out of academic research. It is not something we just came up with during some consulting work. It really comes from academic research building on other researchers' work. We literally got people around the world to use these tools and we helped people do better work. It is kind of mind-boggling sometimes when somebody after a conference comes up and says " Oh, Alex, you really changed my life." First I think, "Well, what's going on?" and then they say, "Well, you know, I work in a different way," or "I could create my company," or "I have a great new job in my company because I've started using these tools." The adoption of the tools is the most fascinating thing and I think that our research should improve the way people work in companies. Due to certain constraints that we have in academic research, we sometimes skip that part, which should be our original intent. That we basically aim to improve the lives - and this is a little exaggerated - but the way people work in companies. I think that we have some influence on that, and we understand now why people adopted these tools.

EM: Using academic results in practice does not necessarily mean that you are able to build a business model out of these results. Could you explain how you were successful in establishing your own business model?

AO: First, let me make clear that we were not the first to write about this topic or to work on this topic. I am very grateful that we could build on other people's work, such as the articles published in Electronic Markets. I think our main contribution was making it practical and getting it adopted. That was the main driver for building the business on top of that. It took a long time to get to these results. No overnight successes, but the focus was always on what is practical and what people really wanted. We were trying to understand how can we put tools into people's hands, and again I am referring to the conceptual tools. We wrote the business model generation book in an extremely visual format, which helped to get it out into the market and get people to buy it. If it had been a book with text, I am not sure we would have had the same success. Yes, the business model canvas played a role in the success, but the visual product was the pillar. Based on that success, we then decided to build a software company on top called Strategyzer. However, building a consulting practice around a concept and a tool, was not as fun as building a software company. Being a software entrepreneur, the vision is to build the SAP of strategy with Strategyzer. What inspires me, and it is a crazy vision and we will probably never get there, but what inspires me is that SAP or Oracle changed the way we do operations. While we had sales automation and all that, I think we can achieve a much better way of working in strategy and innovation as well if we build these kind of management systems that allow us to work around strategy and innovation in a different way. I think it is going to happen and it would be fun if Strategyzer would be one of the main players in this field. Are we there already? No way, we are far away because you have to transform the way people work. Today people not necessarily use tools and processes as much as they should for strategy and innovation. Sometimes the tools and processes are also outdated. First you have to change the way people work, and then you get them to use the software. We were already successful with an iPad app. We got some 40,000 people, now maybe we are at 50,000 people, to buy this iPad app and pay us $\$ 30$ to sketch our business models on a digital tool. That was our first test. Then we said, "OK, test succeeded. But you cannot build a business on the back of an iPad app if you are not a gaming company." We started the software as a service space, and we replicated this application and added many features to it as a service on the Web. We are in this second phase now and we are about to build the third phase, which is to turn this into a publicly available service with some thousand customers, such as Salesforce.com. Since this is an entirely different and more complicated game, we follow a phased approach, where we test every aspect before we move to the next one in order to minimize the risk. This is a fully self-funded company based on the visibility that we received with the business model generation book and some workshops that finance the software.

EM: Could you elaborate on how Strategyzer.com is actually working?

AO: The question is how do people design business models today? Well, putting a business model canvas on the wall and attaching sticky notes to it works fine. However, as soon as you are in a larger company or in a distributed company, you need tools that help you to collaborate, to share what you are doing. Like a computer-aided design tool for architects, Strategyzer lets you sketch out your business models. You can make three or four different prototypes for the same technology. Maybe you can say, "OK, what if I had a business model where I sell my technology? I will make a second 
business model prototype with a subscription. I'll make a third business model prototype that looks a little bit more like Nespresso." You can quickly add numbers to it and, for example, understand what the financial dynamics are. Without actually having to go to a spreadsheet, you can visually sketch out your business model, throw in some estimates and immediately obtain a better understanding of your business model. Once you have this in a system, you can easily collaborate. For example, Mastercard has distributed teams all over the world. How are they going to work on designing a business model if they cannot be all in the same room? This might happen once every month or every quarter. They need a software system that allows them to collaborate online, a better tool than sending around PowerPoint documents. Otherwise, you are confronted with the same mess that we had actually with numbers before SAP. The vision is that you can do this for business models as well and have all strategic concepts in Strategyzer. You can seamlessly navigate from the business model to the value proposition and you can start testing your business model. It is turning the field of business modeling into a more professional field by giving people the conceptual and software-based tools to do this.

EM: From your experience, which were the most interesting business models you saw during the last decade?

AO: In general, I would say that there is no such thing as a right business model. Every context and every industry is different. I would rarely recommend a company to do this or to do that. More important is to give companies a tool to figure out their right business model as a starting point. It is a wrong approach to distinguish between right or wrong business models. It is just like there is no right or wrong building for an architect. Some buildings might be better in some city contexts, with some materials, according to where it is, landscape, but also temperature and climate. Every situation requires a different solution and it is the same with business models. There is no such thing as a right solution. But to answer your question, one of the things that I am really excited about is are business models that aim at two things at a time. One is to make a profit and the other one is to change the world by having a big impact on a big issue. One example I use in my workshops all the time is not a funny example, although it kind of sounds funny-it is a company called Peepoople. This Swedish startup had a technology, which is a so-called peepoo bag. It does what it says, which is addressing one of the biggest issues in the world: some 2.6 billion people do not have access to proper sanitation. Obviously, this is an important issue because there are consequences on health, on economic development, and so on. A Swedish architect came up with this low-tech, single-use toilet bag. He was smart enough to say, "I don't think this is going to work if I just build a charity or a not-for-profit around this product bag, which works." He hired a person called Corinne
Reece from the private sector to figure out a business model that would harmonize profit and impact. The business model should grow and be financially sustainable at the same time and have an impact by giving millions of people access in one way or another to this technology. They raised about $€ 3$ million and now they are figuring out the right business model to change the world by having an impact and making a profit. Sun Edison is another exciting example. Jigar Shah who launched the company had a more ideological goal. It was to get the United States or companies in the United States to adopt solar energy. He came up with a business model that would be profitable and harmonize with profits, even though it had a huge impact in solar energy adoption in companies. He did the same thing and became, with Sun Edison, the biggest provider of solar energy in the United States. He then sold his company, but he aimed for an ideological goal by building a financially sustainable business model. What is attractive is the impact, which is not at the expense of profit. Typically, you might think" Oh, I want to have more impact? I'll have to diminish my profitability." Usually, the first thing you cut in a company when you have to make more profits is Corporate Social Responsibility. If impact is not at the expense of profit, there is nothing to cut in terms of cost, because impact and profitability are harmonized. These business models are extremely exciting compared to the more traditional ones that transform entire industries. Although Nespresso did an amazing job in transforming parts of the coffee industry, their business model has, to a certain extent, expired because their patents have expired. They still rely on brand and now they have to renew themselves. Another inspiring company is Amazon, which has reinvented its business models all the time while being successful. It is phenomenal that an e-commerce company can become one of the most fierce, craziest competitors of IBM. In fact, IBM is afraid of Amazon. This vision of reinventing your business model while you are successful is the kind of vision we would need in Swiss banks and in Swiss pharmaceutical companies. Today, I do not see any Swiss bank or Swiss pharmaceutical company taking the same kind of visionary approach, saying "Our business model needs to have a portfolio of great business models." Companies that re-invent themselves while they are successful are those that inspire me as somebody who is teaching business models. In the same category, you obviously find Apple. It is not the product innovation that makes them interesting, but the fact that they reinvent their business models while they are successful. We often fail to look at those companies from that angle.

EM: Could you identify enablers or prerequisites for a successful and sustainable business model? What are the do's and don'ts? 
AO: A big learning, that we have seen over the last years is to decouple. We need to decouple the product and the technology from the business model. Take Nespresso as an example. They almost failed with the same technology but a different business model. Few people know that they almost went bankrupt. They assumed that it is the product or the technology alone that provides success. Which is nonsense. The first thing you need to do is decouple product and technology from your business model. That means asking yourself what is the best business model for your particular product, technology, or intellectual property. Imagine you are creating a diagnostic device, a medical diagnostic device. You could sell it and you could make a business around that. But what if you had a different business model with recurring revenues? Apply the Nespresso model to a medical diagnostic device by saying "OK, what makes Nespresso strong is that there is a machine and there is a consumable. What happens if we apply the same idea to a medical diagnostic device? Although a machine might be in the hospitals or in the doctors' practice, they would have to buy a consumable every time they use it, just like a Nespresso pod. Your business model will probably create 40 times more profit. This ability to decouple technology and products is a huge thing. For example, I gave a talk at $3 \mathrm{M}$ a couple of months ago. $3 \mathrm{M}$ are amazing product innovators and they know it. What they also know is that they have little ability of asking themselves what the right business model is for different products. They could easily double their revenues if they had that approach. To answer your question there are some characteristics of a sound business model design beyond the fact that people just need to like your product. One is recurring revenues, which are usually much more profitable than transactional revenues. Take GoPro as a popular example, who provide the cameras that our kids want on their ski helmets or that we might have for mountain biking. GoPro is successfully selling their products, but they are in a commodity business. Their whole product is assembled from standardized parts with little differentiation. Over the long term, if GoPro fails to find a better business model that either locks in customers, like Apple did with the iPod by getting us to put all the music on there, they will probably disappear within a year. So, some sound business model designs involve recurring revenues. Another one is switching costs. Ask yourself how easy or difficult it is for your customer to switch. In the case of GoPro it is easy to switch as well as with the cereals you buy every time you go to the supermarket. It is also easy to switch from one brand of your toilet paper to another. It was the same thing for coffee until Nespresso came up with the machines and the pods. Suddenly, it became difficult to switch the coffee grind you use. Another business model mechanic refers to asking how scalable your business model is. Typically consulting is a much less scalable business model than the platform business. For example, WhatsApp was able to service 450 million people with 60 engineers. That is unbelievable scalability, right? These are interesting aspects that you want to analyze in your business model. If you take Facebook, why can they create so much value for so many people? Well, because 1.2 billion people or basically any person who uses Facebook works for them for free. Because the value proposition of Facebook is actually not the platform. It is the content that Facebook users put on the platform. Facebook knows well that they have a free workforce of 1.2 billion people. Therefore, another business model principle asks "How much do you get others to do the work?". The questions allow you to assess how good your business model is. Of course, you always need customers interested in your products. But depending on how you use these business model mechanics, you can make and design a business model, which is 20,40,50, or 100 times more profitable than another one. In summary, you need both: You need great value propositions around products and technologies, and you need a great business model. Again, the problem is that today most people focus on product and technology, and not on the business model.

EM: What expectations or developments do you see for the future of business model research?

AO: The last thing that I would want people to think is that the business model canvas does everything for them. We are convinced that you need many tools that work together and we designed another tool called the value proposition canvas, which works like a plug-in with the business model canvas. What I see in the future is that we have many of these tools, conceptual tools, that all work together in harmony. Rather than reinventing tools or adding boxes here and there to the business model canvas, I say, "No. Why don't you just add a tool that is compatible with the business model canvas?" It is like a surgeon, who enters the operating theater and has many different tools to perform a surgery. I think we are going to have the same thing in the field of business model innovation and business model design. We will have a series of tools and might use the business model canvas or the value proposition canvas, we might use the jobs-to-be-done concept, which we integrated in the value-proposition canvas, and we might have a tool to understand organizational culture. There is much research on organizational culture, but we lack a practical tool that managers or CEOs could use immediately. We will have tools around culture and they will all seamlessly operate together via different real application programming interfaces (API). I believe that we will see more of these concepts, which we like to call management objects. They will be interoperable and they will be inside computer systems. We will have real management information systems to design, test, and manage these management objects. That is where I think the whole field is going and I expect great research happening. Today, it is not sufficiently consolidated and you would also like to see more interoperability. I think 
we will have more tools and I would like to see more of them interoperable. While we are trying to do our piece, we are also trying to get others to design tools as well. The more great thinkers with great concepts are involved, the more people start adopting them in companies.

EM: What would be your wish list for academic research in the business model domain and which contribution would you expect from research in the future?

AO: First, I would expect a better understanding of networks of business models. While much research has gone into networked business models, a practical approach would motivate real-world companies to think about networks. In particular, I would like to see more work regarding portfolios of business models. Company, such as Nestlé, pursue many business models and I doubt whether they are aware of how to manage a portfolio of business models. They might be aware of managing their brand portfolio and their product portfolio, but I know that they are not actively managing a business model portfolio. In general, the diffusion of these kind of management objects or tools, such as the business model canvas, is a big challenge. What motivates managers, project leaders, product innovators, product teams or product designers to use these tools? If we really want people to use MIS in strategic contexts, we first have to understand what motivates them to change the way they work and to adopt the conceptual tools. Often, it requires a different way of working before you even start thinking of adopting a MIS. This is something we learned the hard way with Strategyzer. While we might have a great vision about being the SAP of strategy, nobody is going to care about a system if they are not already working in a structured way to design their business models. Traditionally, the process is very ad hoc: you set up a meeting, you brainstorm, and you might agree on some actions. When people are starting to become structured, they are using the business model canvas to sketch out and to test their business models. We realized that companies, such as MasterCard, are now rolling out the business model canvas as a shared language. They trained 500 people in their company to use the business model canvas and the value proposition canvas as a method, because they want people to have a shared language and to work beyond technologies and features. It was an eye opener. As trivial as it sounds, people need to learn about these concepts first and only want software-based tools afterwards. They desire the systems as soon as they face problems using the paper-based tools. But if they fail to even use paper-based tools conceptually, well, there is no need for a system. You will not start transforming an organization with the system. You start by transforming an organization by the way they work.
EM: How can academic research in the electronic markets field be more relevant for practitioners in the future or, more general, how can academic research have impact on the real world?

AO: Recently, Yves Pigneur used the value proposition canvas with academic researchers. They would ask themselves, what their value proposition to practitioners was. This question is often dropped because we have the constraints of publishing. We went the extra length to publish stuff that is relevant and that has certain impact on the world. In any case, academics need to keep their rigor, since many consultants also suggest models, but which lack the rigor of having them conceptually sound and derived from existing research. What academics really should ask themselves is whether they want to have an impact. In principle, you can survive in academia without asking yourself that question and focus on publishing and advancing your career. This is fine, but, as soon as you aim at having an impact, we really need to ask ourselves about our value proposition to practitioners and answer it like an entrepreneur. Thinking hard about your products is not enough; you need to go out every day and show them to practitioners. This is a humbling experience and numerous times people told my team and myself, "Oh, this? That's plain wrong." or "That sucks." or "We don't believe in that." Sometimes I think that in academia we are protected from this permanent need to stress test our ideas with practitioners. Yet if we do, we learn and receive input to work on things that will be adopted. Nevertheless, this is a painful process. Entrepreneurs have to deal with this, because otherwise they disappear. In academia, we have a dual role: We want to have an impact, but we also want to publish and advance our careers. Sometimes we can survive with the first one, publishing, without having to survive with the second one. I think there are some highly valuable aspects that force academics to actually stress test some of their work in practice. There is still a long way to go, particularly, in the field of business model research.

EM: Alex, thank you very much for the interview.

\section{Reference}

Osterwalder, A. (2004). The business model ontology - A proposition in a design science approach. Doctoral thesis. Université de Lausanne.

Osterwalder, A., \& Pigneur, Y. (2010). Business model generation: A handbook for visionaries, game changers, and challengers. New York: Wiley. 